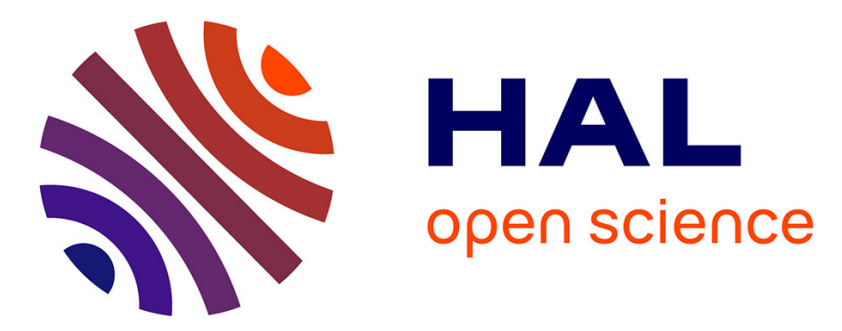

\title{
Actuator fault detection, isolation method and state estimator design for hot rolling mill monitoring
}

Didier Theilliol, Mahdi Mahfouf, Dominique Sauter, Miguel Angel Gama

\section{To cite this version:}

Didier Theilliol, Mahdi Mahfouf, Dominique Sauter, Miguel Angel Gama. Actuator fault detection, isolation method and state estimator design for hot rolling mill monitoring. 6th IFAC Symposium on Fault detection, Supervision and Safety of Technical Processes, Aug 2006, BEIJING, China. pp.CDROM. hal-00095578

\section{HAL Id: hal-00095578 https://hal.science/hal-00095578}

Submitted on 16 Sep 2006

HAL is a multi-disciplinary open access archive for the deposit and dissemination of scientific research documents, whether they are published or not. The documents may come from teaching and research institutions in France or abroad, or from public or private research centers.
L'archive ouverte pluridisciplinaire HAL, est destinée au dépôt et à la diffusion de documents scientifiques de niveau recherche, publiés ou non, émanant des établissements d'enseignement et de recherche français ou étrangers, des laboratoires publics ou privés. 


\title{
ACTUATOR FAULT DETECTION, ISOLATION METHOD AND STATE ESTIMATOR DESIGN FOR HOT ROLLING MILL MONITORING
}

\author{
D. THEILLIOL $\left({ }^{\circ}\right)$, M. MAHFOUF(+), D. SAUTER( $\left(^{\circ}\right)$, M.A. GAMA(+)
}

\author{
(') Centre de Recherche en Automatique de Nancy (CRAN - UMR 7039) Nancy-University, CNRS \\ BP 239 - 54506 Vandoeuvre Cedex - France. \\ Phone: +33383684465-Fax: +33383684462 \\ (+) IMMPETUS - Department of Automatic Control and Systems Engineering \\ University of Sheffield, Sheffield S1 3JD, UK.
}

email: didier.theilliol@,cran.uhp-nancy.fr

\section{INTRODUCTION}

Monitoring is necessary to ensure effectiveness of process control and consequently a safe and a profitable plant operation. Sensor or actuator failure, equipment fouling, feedstock variations, product changes and seasonal influences may affect controller performance and as many as $60 \%$ of industrial controllers problem (T.J. Harris et al., 1999). The diagnosis of such problems from raw data trends is often difficult, however model-based approach among fault diagnosis methods or Fault Detection and Isolation (FDI) techniques are considered and combined to supervise the process and to ensure reliability, availability, and safety in industrial plants (D. Theilliol et al., 1997). A short historical view on FDI can also be found in (Iserman and Ballé; 1997) and currents developments are reviewed in (Frank et al., 2000).

The main aim of this paper is to develop an actuator fault diagnosis technique for a Single Input Multiple Output (SIMO) system under disturbances. The design is adapted to the hot rolling Hille mill of IMMPETUS (Institute for Microstructural and Mechanical Process Engineering) at the University of Sheffield. The purpose of the hot rolling mill is to produce a steel plate from a preheated steel block that is to make it thinner and longer. The plate thickness is reduced by pulling the plate between two parallel rolls at a specific rolling speed and temperature. The plate thickness is controlled by moving the upper work roll. For many years, several modern thickness control systems ((Grimble and Hearns., 1998), (Stephens and Randall, 1997)) have been designed to perform such a production, however only few research activities have been dedicated to consider a fault occurrence in the closed-loop and their consequence on the steel plate. Among the critical rolling process variables, such as the characteristic of mill drive, or the rolled slab, or the deformation temperature, the roll speed plays an important role in the metal microstructure of the final product. This paper proposes to solve the problem of actuator fault diagnosis in a speed control loop. Based on a large diversity of advanced model-based methods for automated FDI, (Chen et al., 1999), (Gertler, 1998), the problem of actuator fault detection and magnitude estimation for linear time invariant systems can be defined as a basic one, nevertheless, it is not the case for the IMMPETUS hot rolling Hille mill. Indeed, due to difficulties inherent to the on-line identification in closed-loop systems, parameter estimation techniques are not suitable. With respect to parity space technique, this approach is suitable to distinguish between different faults in the presence of uncertain parameters, but not useful for fault magnitude estimation. Whereas, the observer-based method seems to be dedicated to our objective, the classical decoupled techniques such as Unknown Input Observer devoted to detect, isolate and to estimate faults (considered as unknown input) cannot fulfil our objective. As presented in Section III, because of the Unknown Input Observer design procedure, for the considered Single Input Multiple Output system with actuator faults, the state decoupled from unknown input (fault) cannot be estimated correctly, due to observability problem and consequently is not enabled to generate an accurate fault magnitude estimation. Hence, in order to reach our objective, a fault detection filter has been considered and has been associated with a classical Luenberger observer. Fault detection filter gains are designed to have the filter residual in an invariant direction in the presence of an element from a set of a priori known faults. Moreover, the gain of the fault detection filter is not synthesised to decouple the state vector from the fault. Based on an appropriate gain synthesis, an actuator fault detection filter is developed, inspired from (Keller, 1999) that makes it possible to detect and to estimate a particular and abrupt fault among disturbances. Combined with a conventional Luenberger observer, a software sensor design on the process can de defined through accurate state space estimation.

The paper is organized as follows. Section II describes the Hille Mill Single Input Multiple Output system and the actuator faulty state space representation. Section III is devoted to the specific actuator fault detection filter design. Finally, simulation experiments are given in Section IV to illustrate the effectiveness and performance of fault detection filter. Conclusions and further work are discussed in Section V.

\section{THE HOT ROLLING HILLE MILL}

\subsection{Brief description}

The experimental hot rolling Hille mill, presented in Fig 1, used to carry out multi-pass forward-forward or forward-reverse rolling and also complex multi-pass rolling experiments, has a three-phase $20 \mathrm{hp}$ induction motor for main drive, reduction gears for roll speed adjustment (between 2 63 rpm from the fixed motor speed of $1500 \mathrm{rpm}$ ) and two rolls with a diameter of $139 \mathrm{~mm}$. The maximum torque of the Hille mill is $3467 \mathrm{Nm}$, and the maximum load of 50 tonnes. The roll gap is adjusted by a $0.5 \mathrm{hp}$ motor via a worm-wheel screw-down mechanism linked to the top roll. In this paper, particular attention is focused on the roll 
speed part. the mechanical configuration of the experimental hot rolling Hille mill sketches with three mass as the motor, the reduction gear and the rolls.

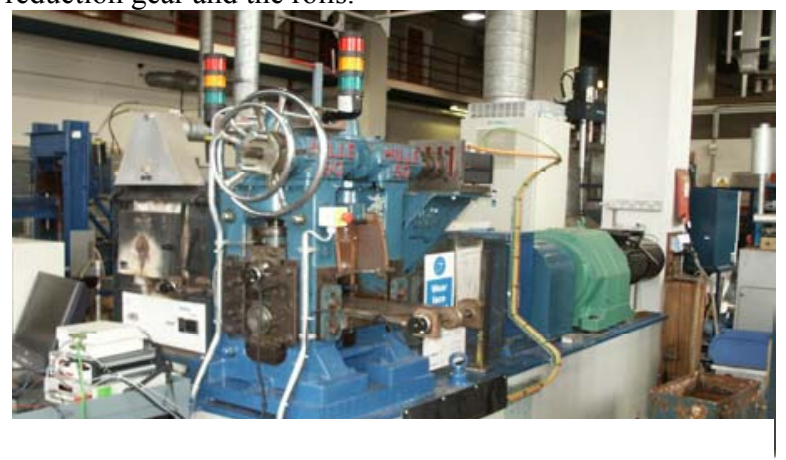

Fig. 1. Hille mill mechanical configuration.

The main feedback roll speed control is based on a cascade control structure with an inner current/torque control loop and an outer speed control loop. The electromechanical torque is the natural response of the motor to compensate any torsional force applied in its shaft and it is directly related with the Hille mill rotational system. The motor drive module, incorporating advanced motor control (closed-loop vector control), ensures the command following ability of the motor drive torque. As illustrated in Fig. 2, based on the roll torque estimation performed by a multilayer neural network model (Mahfouf et al., 2005), a feedforward control loop is cancelling its effects upon the roll speed to achieve a fast speed response and to have better disturbance rejection ability coming from the load torque fluctuation during rolling.

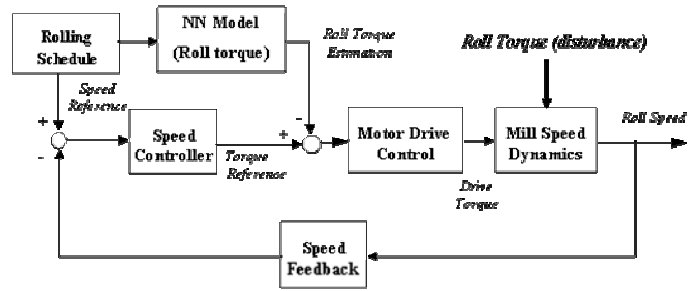

Fig. 2. A block diagram of the roll speed control loop.

\subsection{Roll speed modeling}

A traditional way of developing the roll speed model is to divide the rolling mill into several mechanical components coupled by flexible shafts, and then to develop the motion equations using Newton's law. In this case by applying Newton's motion law, the rotational system is represented by the following equations:

$$
\begin{aligned}
& J_{m} \frac{d \omega_{m}}{d t}=-\mu_{m} \omega_{m}-T_{s h m}-T_{e} \\
& T_{s h m}=K_{s h m}\left(\frac{d \omega_{m}}{d t}-\frac{d \omega_{g}}{d t}\right) \\
& J_{g} \frac{d \omega_{g}}{d t}=-\mu_{g} \omega_{g}+T_{\text {shm }}-\frac{T_{s h r}}{R_{g}} \\
& T_{s h r}=K_{s h r}\left(\frac{1}{R_{g}} \frac{d \omega_{g}}{d t}-\frac{d \omega_{r}}{d t}\right) \\
& J_{r} \frac{d \omega_{r}}{d t}=-\mu_{r} \omega_{r}-T_{s h r}-T_{\text {load }}
\end{aligned}
$$

where $\omega, J$ and $\mu$ are the speed, inertia and friction coefficient of the motor $(m)$, gear $(g)$ and roll $(r)$ shafts respectively, $R_{g}$ is the gear box ratio (constant during experiment), $T_{\text {load }}$ is the torque applied to the rolls when a slab is rolled, $T_{s h m}$ and $T_{s h r}$ are the strain torque of the motor and roll shaft respectively. The model parameters, such as the inertia, the stiffness of the shafts and the frictions of the individual components are supposed to be known and constant (Mahfouf et al., 2005). 
According to the sensors available on the experimental hot rolling Hille mill, a roll speed discrete state space representation can be established as follows:

$$
\begin{aligned}
x_{k+1} & =\mathrm{A} x_{k}+\mathrm{B} u_{k}+\mathrm{D} d_{k} \\
y_{k} & =\mathrm{C} x_{k}
\end{aligned}
$$

where $x=\left[\begin{array}{lll}\omega_{m} & \omega_{r} & T_{s h r}\end{array}\right]^{T}$ is the state space vector, $u=T_{e}$ is the input vector, $d=T_{\text {load }}$ in the non measurable disturbance (unknown input) with $\mathrm{D}$ its associated and constant distribution matrix, and $y=x$ is the output vector. An accurate sampling period equal to $0.001 \mathrm{~s}$ according to the dynamic performance in closed-loop has been determined to calculate the various matrices.

Due to the abnormal operation or to material aging, actuator faults can occurs on the system. An actuator fault can be represented by additive and/or multiplicative faults as follows:

$$
u_{k}^{f}=\alpha_{k} u_{k}+u_{0}
$$

where $u_{k}$ and $u_{k}^{f}$ represent the normal and fault control actions, respectively. $u_{0}$ denotes a constant offset and $0 \leq \alpha_{k} \leq 1$ denotes a gain degradation of the actuator (constant or variable). Therefore, in faulty case, the roll speed discrete state space representation becomes as:

$$
\begin{aligned}
x_{k+1} & =\mathrm{A} x_{k}+\mathrm{B} u_{k}+\mathrm{F} f_{k}+\mathrm{D} d_{k} \\
y_{k} & =\mathrm{C} x_{k}
\end{aligned}
$$

where $F$ represents the fault distribution matrix (equal to $B$ ) and $f$ is the faulty vector. The problem is to diagnose the fault in terms on fault detection and fault magnitude estimation among many factors which affect the rolled slabs and both to estimate accurate state space.

\section{A FAULT DETECTION FILTER COUPLED WITH AN OBSERVER:} A TOOL FOR MONITORING.

\subsection{Problem statement}

In this paper, a class of faulty systems is considered where an actuator fault can be classically represented as an additive unknown input term in a discrete dynamic equation described as follows:

$$
\begin{aligned}
x_{k+1} & =A x_{k}+B u_{k}+F f_{k} \\
y_{k} & =C x_{k}
\end{aligned}
$$

where $x \in \mathfrak{R}^{n}$ is the state vector, $y \in \mathfrak{R}^{m}$ is the output vector, $u \in \mathfrak{R}^{p}$ is the input vector and $f \in \mathfrak{R}^{q}$ is the actuator fault vector. $A, B, C$, and $F$ are known matrices with appropriate dimensions. In the following, the number of faults is assumed to be less than the number of state, such as:

$$
\operatorname{rank}(C F)=\operatorname{rank}(F)=q
$$

Therefore, if $(C, A)$ is observable, a conventional stable Luenberger observer can detect the fault by monitoring the residual ( $r=y-\hat{y}$ with $\hat{y}$ defines estimated output). A more difficult task is to determine also the fault magnitude estimation and to estimate state space vector: an Unknown Input Observer achieves this main objective. Under necessary and sufficient conditions, defined in the book by (Chen et al., 1999), an unknown input (considered as a fault) full-order observer can be written as follows:

$$
\begin{aligned}
w_{k+1} & =\mathrm{E} w_{k}+\mathrm{TB} u_{k}+\mathrm{K} y_{k} \\
\hat{x}_{k} & =w_{k}+\mathrm{H} y_{k}
\end{aligned}
$$

where $\hat{x}$ is the estimated state vector and $w$ is the state of this full-order observer. $\mathbf{E}, \mathbf{T}, \mathrm{K}$ and $\mathrm{H}$ are matrices to be designed for achieving unknown input decoupling requirements. That is to say, the state estimation error vector $(e=\hat{x}-x)$ of the observer goes to zero asymptotically, regardless of the presence of the unknown input in the system. The unknown input observer design is achieved by solving the following equations:

$$
\begin{aligned}
& (H C-I) F=0, \\
& T=I-H C, \\
& E=A-H C A-K_{1} C, \\
& K_{2}=E H,
\end{aligned}
$$




$$
\text { If } K=K_{1}+K_{2}
$$

$$
(C, A-H C A) \text { is observable, }
$$

an Unknown Input Observer exist. Moreover, through an appropriate Singular Value Decomposition, see Theilliol et al., 2002, accurate fault magnitude estimation is generated. If (17) is not fulfilled, (Chen et al., 1999) have proposed a solution based on canonical decomposition procedure, However, a reduced-order observer is established and the decoupled state vector is not completely estimated.

Hence, in this paper, in order to reduce the lack of available variables and to increase the efficiency of monitoring, we proposed a solution which does not generally fit the usual paradigm where the fault diagnosis method relies on an unique technique. Therefore, to deal with the drawback to use an unique decoupled observer to detect, isolate and estimate fault magnitude and state vector, we suggested to combine the effectiveness of a particular fault detection filter with the conventional Luenberger observer.

\subsection{Solution design}

In order to detect and to estimate the fault magnitude, we propose to design a fault detection filter which does not decouple the residuals from fault but assigns the residuals vector in particular directions to guarantee the identification of the fault. Then, the observer gain $K_{1}$ with $\mathrm{T}=\mathrm{I}$ and $\mathrm{H}=0$ is synthesized such the residual vector $r_{k}=y_{k}-C \hat{x}_{k}$ is insensitive to $f_{k}$, but the projectors $R$ are designed such that the projected residual vector $q_{k}=R r_{k}$ is sensitive only to a particular fault direction. The fault detection filter further will be useful to deal with the problem of the fault magnitude estimation.

Under this assumption, the estimation error vector and the residual vector are calculated from (11) as follows:

$$
\begin{aligned}
& e_{k+1}=\left(A-\mathrm{K}_{1} C\right) e_{k}+F f_{k} \\
& r_{k}=C e_{k}
\end{aligned}
$$

In the fault-free case and for notation purposes, the estimation error vector is written as $\bar{e}_{k}$ and the residual vector is noted $\bar{r}_{k}$. Under the assumption that an actuator fault occurs at time $k_{f}\left(k>k_{f}\right)$, the residual vector is expressed as follows:

$$
r_{k}=\bar{r}_{k}+\rho_{k}^{k_{f}}\left[\begin{array}{llll}
f_{k_{f}} & f_{k_{f}+1} & \cdots & f_{k}
\end{array}\right]
$$

where

$$
\rho_{k}^{k_{f}}=C\left[\begin{array}{c}
\Gamma_{k}^{k_{f}+1} F \\
\Gamma_{k}^{k_{f}+2} F \\
\ldots \\
F
\end{array}\right]
$$

with

$$
\Gamma_{k}^{k_{f}}=\prod_{\tau=k_{f}}^{k-1}\left(A-\mathrm{K}_{1} C\right)
$$

Equation (20) allows us to confirm that the residual vector is affected by the fault effects. We wish to design the residual vector in an invariant direction such as it is insensitive to the fault effects, such that:

$$
\left(A-\mathrm{K}_{1} C\right) F=0
$$

In order to perform equation (23), $K_{1}$ is decomposed into two gains as:

$$
K_{1}=K_{A}+K_{C}
$$

Therefore, equation becomes:

$$
A F-\mathrm{K}_{A} C F-\mathrm{K}_{C} C F=0
$$

where $\mathrm{K}_{\mathrm{A}}$ should be defined in order to obtain $A F-\mathrm{K}_{A} C F=0$, and respectively $\mathrm{K}_{C}$ to $\mathrm{K}_{C} C F=0$.

As proposed by (Keller, 1999), based on (10) we can define in the deterministic case the following:

$$
K_{A}=\omega \Xi
$$

with $\omega=A F$ and $\Xi=(C F)^{+}$

respectively: 
where $\Psi=\beta\left(I_{m}-(C F)(C F)^{+}\right)$, it is noted that $\beta$ is chosen as a matrix composed of one with $\beta \in \mathfrak{R}^{m-q . m}$, compared to (Keller, 1999) in the stochastic case, no other conditions are needed.

With respect to $K$, this reduced gain defines the unique free parameter in this specific observer and will be synthesised in a common way.

From equation (24), and the $T$ and $H$ matrices properties, the observer, defined in (11), can be expressed as follows:

$$
\begin{aligned}
\hat{x}_{k+1} & =\mathrm{A} \hat{x}_{k}+\mathrm{B} u_{k}+\left(\mathrm{K}_{\mathrm{A}}+\mathrm{K}_{\mathrm{C}}\right)\left(y_{k}-C \hat{x}_{k}\right) \\
\hat{y}_{k} & =\mathrm{C} \hat{x}_{k}
\end{aligned}
$$

Based on (26) and (27), (28) becomes equivalent to:

$$
\begin{aligned}
\hat{x}_{k+1} & =(\overline{\mathrm{A}}-K \overline{\mathrm{C}}) \hat{x}_{k}+\mathrm{B} u_{k}+\mathrm{K}_{\mathrm{A}} y_{k}+K \Psi y_{k} \\
\hat{y}_{k} & =\mathrm{C} \hat{x}_{k}
\end{aligned}
$$

with $\bar{A}=A\left(I_{m}-F \Xi C\right)$ and $\bar{C}=\Psi C$. Gain $K$ is synthesis by a common eigenstructure assignment in order that:

$$
(\overline{\mathrm{A}}-K \overline{\mathrm{C}}) \text { is Hurwitz. }
$$

The gain decomposition, defined in (24) and associated definitions involves the following matrices properties:

$$
\Xi C F=0 \text { and } \Psi C F=I
$$

and from (20) makes possible the generation of projected residual vector as follows:

$$
q_{k}=R r_{k}=\left[\begin{array}{c}
\Psi \\
\Xi
\end{array}\right] r_{k}=\left[\begin{array}{c}
\Sigma \bar{r}_{k} \\
\Xi \bar{r}_{k}+f_{k-1}
\end{array}\right]=\left[\begin{array}{l}
\gamma_{k} \\
\eta_{k}
\end{array}\right]
$$

It can be noted that $\gamma \in \mathfrak{R}^{m-q}$ is a residual insensitive to faults.

This residual vector is an efficient indicator to detect the quality of the fault detection filter. Indeed, if a fault occurs on the system, but is not defined in the state space equation (9), then $\gamma_{k} \neq \Sigma \bar{r}_{k}$ and also $\eta_{k} \neq \Xi \bar{r}_{k}+f_{k-1}$. A simple residual evaluation technique should be computed in order to indicate the accuracy of projected residual vector $q_{k}$, more precisely the accuracy of the last component. With respect to the last component, $\eta \in \mathfrak{R}^{q}$ represents the fault estimation vector (with a delay of one sample according to an actuator fault detectability indexes (Liu and Si, 1997)), this vector should be exploited for fault diagnosis. Indeed, a residual evaluation algorithm can be performed by the direct fault magnitude evaluation through statistical test in order to supervise the process. However, it can be noted that the proposed filter cannot generate an accurate state space. In a stochastic case, (Sauter et al., 2005) have disabled this problem by handling matrices which involves on-line inversion matrices. In this paper, to achieve this purpose, we propose that the fault detection filter works in tandem with conventional Luenberger observer estimator. Based on a very simple idea, under the schedule of $\gamma_{k}$ residual evaluation, the available $\eta_{k}$ fault estimation is injected as an other known input in Luenberger observer, such as:

$$
\begin{aligned}
\hat{x}_{k+1} & =\mathrm{E} \hat{x}_{k}+\mathrm{B} u_{k}+\mathrm{K} y_{k}+F \eta_{k} \\
\hat{y}_{k} & =C \hat{x}_{k}
\end{aligned}
$$

Based on this technique, a system defined in (8) could be represented as in (9) by an augmented unknown input vector. If conditions (10) and (30) are fulfilled, the fault detection filter should be used to detect actuator fault and to estimate both the fault magnitude as well as the disturbance.

\section{SIMULATION RESULTS}

For illustration purposes, different scenarios have been conducted in a simulation platform. This simulation platform describes the rolling process behavior of the Hille mill without affecting the real plant. On the real plant, a sensor strain torque $T_{s h r}$ of the motor exists, but in order to detect some malfunctions, this data should not be considered as a reliable sensor and not an available measurement, consequently, the output vector can be expressed as follows:

$$
y=\left[\omega_{m} \omega_{r}\right]^{T}
$$

4.1 "known" roll torque $T_{\text {load }}$

At first, the roll torque $T_{\text {load }}$ is supposed to be known (measurable) and the model-based roll speed is used to estimate actuator fault $f$ and state space as follows: 


$$
\begin{gathered}
x_{k+1}=\mathrm{A} x_{k}+\underbrace{\left[\begin{array}{ll}
B & D
\end{array}\right]}_{B} \underbrace{\left[\begin{array}{c}
u_{k} \\
T_{\text {load }}
\end{array}\right]}_{u}+\mathrm{F} f_{k} \\
y_{k}=\mathrm{C} x_{k}
\end{gathered}
$$

For the experimental hot rolling Hille mill, the conditions (10) and (30) are fulfilled, the fault detection observing filter is tested in fault-free and faulty cases.

\section{a- Actuator fault-free case}

Various step responses of the roll speed subsystem are studied and disturbances are considered. Without an actuator fault, all simulations are performed for a four rolling multi-pass operations with a first roll speed at $30 \mathrm{rpm}$ and $5 \mathrm{rpm}$ less at each step, together with a reduction of $10 \%$ starting at $40 \%$. From the simulation results of Fig. 3, it is apparent that under a classical PID control the roll speed responses are close to the reference and ensure an accurate performance despite the roll torque force. The disturbances for each step simulate roll pass (see the zoomed part in Fig. 3).

In the fault-free case, the two components $\left(\gamma_{k}\right.$ and $\left.\eta_{k}\right)$ of the projected residual vector are equal to zero means (note presented here). In order to assess the method, more exactly the state space effectiveness, a sensor fault on $T_{s h r}$ (which it is not involved in the output vector $y=\left[\begin{array}{ll}\omega_{m} & \omega_{r}\end{array}\right]^{T}$ ) is supposed to occur at instant $10 \mathrm{~s}$ and disappear at instant 30s. As defined in (7), but for a sensor, a constant gain on the strain torque of the motor $T_{s h r}$ is created and added with $\alpha=0$ and $\mathrm{y}_{0}=100$, otherwise $\mathrm{y}_{0}=0$. This fault, a bias, cannot be directly observed in Fig. 3 because the corrupted sensor is not involved as an output in the speed control loop. Based on a appropriate conventional Luenberger observer with $y=\left[\begin{array}{ll}\omega_{m} & \omega_{r}\end{array}\right]^{T}$, the developed technique provides an accurate state space vector: the residual vector is equal to zero mean. The developed technique provides an accurate $\hat{T}_{s h r}$ insensitive to sensor fault. A residual vector $r=\hat{T}_{s h r}-T_{s h r}$ can be generated to illustrate directly the sensor fault as presented in Fig. 4. According to $r=\hat{T}_{s h r}-T_{s h r}$, a simple test evaluation can be used to detect this fault.

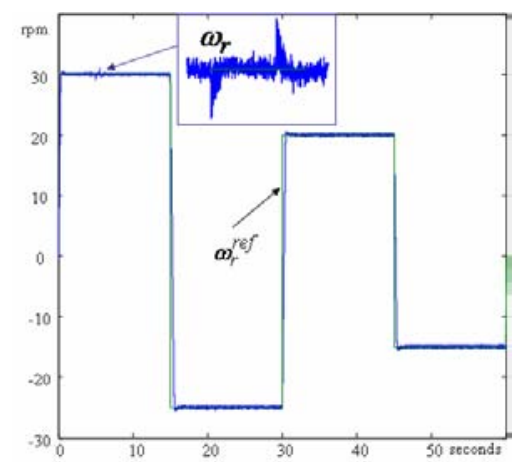

Fig. 3. Dynamic behaviour of Roll speed and its reference in the fault-free case.

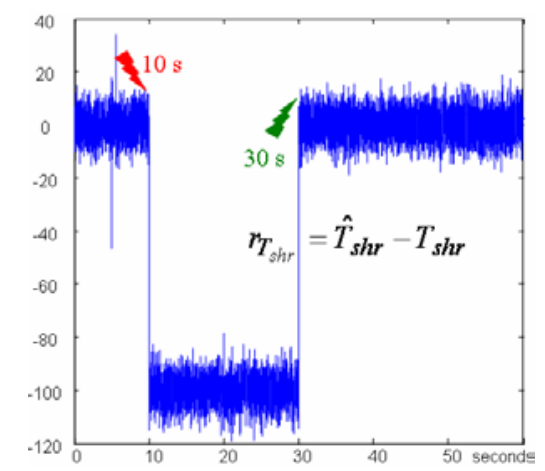

Fig. 4. Residual on sensor torque $T_{\text {shr }}$. 


\section{b- Actuator faulty case}

A gain degradation of the motor due to material ageing or a failure in a component equivalent to $50 \%$ loss of effectiveness is supposed to occur at instant $2 \mathrm{~s}$ just before the first rolling and to disappear at time 30 s during a step. To do so without damaging the system, the control input applied to the system is equal to the control input computed by the controller multiplied by a constant system $\left(\alpha=0.5\right.$ and $\left.\mathrm{u}_{0}=0\right)$. The consequence of an actuator fault on the speed control loop is illustrated in Fig. 5 with a zoom presented in Fig 6. Despite the fault, the effect is not significant in the steady state due to the motor drive control strategy based on drive torque, as illustrated in Fig. 5. However, since an actuator fault acts on the system as a perturbation, and due to the presence of the integral error in the controller, the system outputs reach again their nominal values when the slab is presented to the rolling process (see Fig. 5).

Compared to the dynamic behaviour in the fault-free case, see Fig. 3, the actuator fault affects the experiment and needs to be detected on-line.

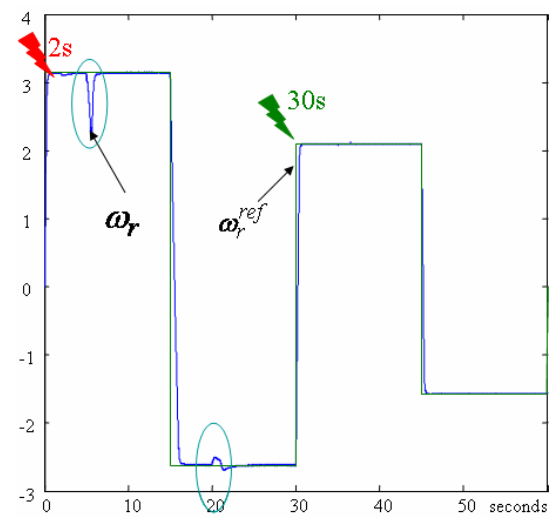

Fig. 5. Dynamic behaviour of Roll speed and its reference in the faulty case

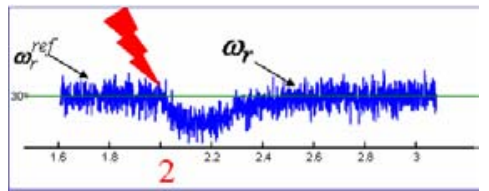

Fig. 6. Zoom of Fig 5 around the fault occurrence.

Based on the experimental data set given as an example, the fault detection observing filter provides the projected residual vector with the residual vector $\gamma_{k}$ equal to zero means and accurate state space vector (not presented here). As mentioned in the previous section, an important feature of the fault detection observing filter is the capability to generate an accurate fault estimation. As illustrated in Fig. 7 (and associated zoom in Fig 8), the fault estimation $\hat{f}$ is close to zero in the fault-free case and is close to the fault magnitude, represented by $\alpha \times u_{k}$, when the failure has occurred.

The simulation results show that the actuator fault detection filter is very effective in detecting and estimating the fault magnitude under disturbances constraints for the whole operating conditions. The fault magnitude estimation should be evaluated through a classical statistical threshold test in order to generate alarms for the operating system.

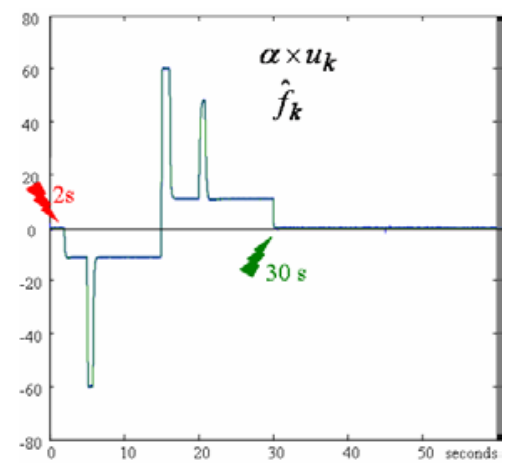

Fig. 7. Fault magnitude estimation and "real" fault with $50 \%$ loss of effectiveness.

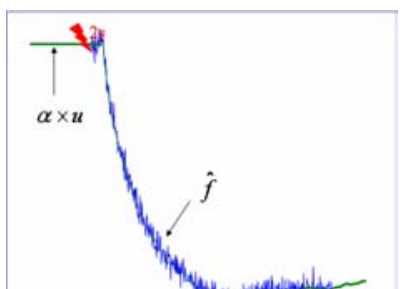


Fig. 8. Zoom of Fig 7 around the fault occurrence.

\section{2 “unknown” roll torque $T_{\text {load }}$}

In this last study, the roll torque $T_{\text {load }}$ is supposed non measurable as on the real plant. Hence, the following model-based roll speed is used to estimate the actuator fault $f$, roll torque unknown input $T_{\text {load }}$ and state space vector $x=\left[\begin{array}{lll}\omega_{m} & \omega_{r} & T_{\text {shr }}\end{array}\right]^{T}$ :

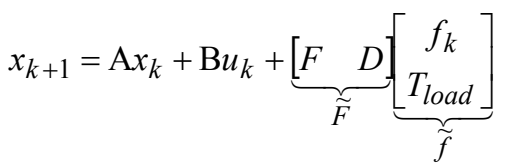

For the experimental hot rolling Hille mill, condition (10) is fulfilled, but the number of outputs is equal to the number of unknown inputs, therefore $\Psi=0$. In this specific case, $(\overline{\mathrm{A}}-K \overline{\mathrm{C}})=\overline{\mathrm{A}}$, hopefully $\overline{\mathrm{A}}$ is stable.

Under noisy conditions, an accurate roll torque magnitude estimation (second component of the vector $\tilde{f}$ in (36)) is performed by the fault detection filter, as presented in Fig. 9. In addition, the first component of vector $\widetilde{f}$, the actuator fault, is close, but not equal, to the fault as illustrated in Fig. 10. This problem is due to the fact that $(\overline{\mathrm{A}}-K \overline{\mathrm{C}})=\overline{\mathrm{A}}$. Indeed, in order to maintain a consistent performance of the fault magnitude estimation, a classical eigenstructure needs to be assigned. But, as mentioned above, the convergence of $e_{k}(18)$ is affected and has a severe effect on the estimator.

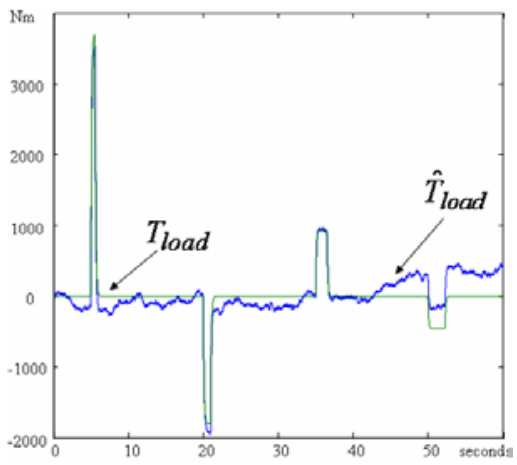

Fig. 9. Roll torque and its estimation.

In assessing the performance of the method, let us consider $y=x=\left[\begin{array}{lll}\omega_{m} & \omega_{r} & T_{s h r}\end{array}\right]^{T}$, under no sensor fault and a new filter, without the $(\overline{\mathrm{A}}-K \overline{\mathrm{C}})=\overline{\mathrm{A}}$ drawback, can be synthesised. Fig. 11 shows the performance of the fault detection filter to estimate an exact roll torque $T_{\text {load }}$. According to a scheduled variable issued from the projected residual vector, the fault detection observing filter provides some information which should be easily integrated in an efficient operator decision aid (Theilliol et al., 1997) to supervise the hot rolling mill.

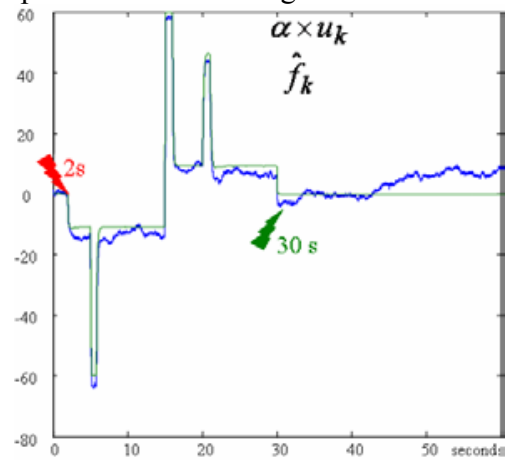


Fig. 10. Fault magnitude and its estimation with $50 \%$ loss of effectiveness.

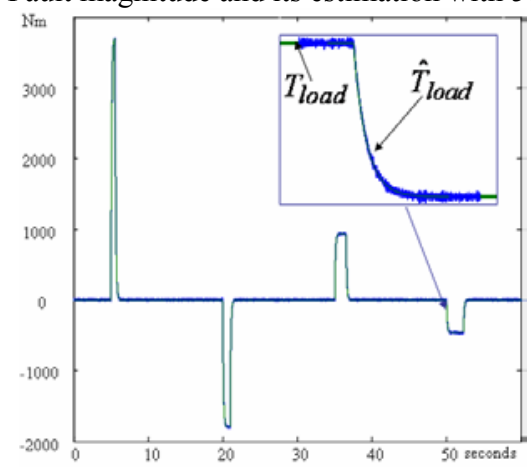

Fig.11. Roll torque and its estimation with $y=x$.

\section{CONCLUSION}

There have been a number of techniques developed over the past decade for fault detection and isolation various systems. Most have proposed to solve FDI problem with a unique "tool" contribution, but the approach described here is different. The proposed method, developed first for a specific application, is not enough innovative but does not require the complex handling matrices when the UIO reduced-order observer needs to be built for specific properties. However, through, its simple fault detection filter working in tandem with a conventional Luenberger observer, the developed technique has proved to be effective for FDI, state estimation and robust against disturbances. According to a scheduled variable issued from a projected residual vector, the fault detection observing filter provided an efficient tool in the operator's decision hot rolling mill process.

\section{REFERENCES}

Chen J., and R.J. Patton (1999) Robust model-based fault diagnosis for dynamic systems. Kluwer academic publishers.

Frank, P.M., S.X. Ding and B. Köppen-Seliger (2000) Current developments in the theory of FDI. In: Safeprocess'2000 IFAC Symposium, Budapest, Hungary, vol. 1, pp. 16-27.

Gertler J.J. (1998). Fault detection and diagnosis in engineering systems. Marcel Dekker, Inc. New York Basel Hong Kong.

Grimble M.J. and G. Hearns. (1998), LQG Controllers for state-space systems with pure transport delays: application to Hot strip mills, Automatica, vol. 34, n¹0, pp. 1169-1184.

Harris T.J., Seppala C., Desborough L.D., (1999). A review of performance monitoring and assessment techniques for univariate and multivariate control systems. Journal Process of Control, vol. 9, pp. 1-17.

Isermann R., and P. Ballé, (1996), Trends in the application of model based fault detection and diagnosis of technical processes. $13^{\text {th }}$ Triennal World Congress IFAC, San Francisco, USA, pp.1-12.

Keller J.Y. (1999), Fault isolation filter design for linear stochastic systems. Automatica, vol. 35, pp. 1701-1706.

Liu B. and Si J. (1997), Fault isolation filter design for linear time-invariant systems. IEEE Transactions on Automatic Control, vol. 42, n5, pp. 704-707.

Mahfouf M., Y. Yang, M.A. Gama, D.A. Linkens (2005), Roll Speed and Roll Gap Control with Neural Network Compensation, The Iron and Steel Institute of Japan International, Vol. 45, No. 6, pp. 841-850.

Sauter D., H. Jamouli, J.Y. Keller, J.C. Ponsart (2005), Actuator fault compensation for a winding machine, Control Engineering Practice, Vol. 13, No. 10, pp. 1307-1314.

Stephens R.I. and Randall A. (1997), On-line adaptive control in the hot rolling of steel, IEE Proceeding Control Theory and Applications, Vol. 144, no. 1.

Theilliol D., Aubrun C., Giraud D., Ghetie M. (1997). DIALOGS: a fault diagnosis Toolbox for industrial process. 3e IFAC Symposium on Fault Detection Supervision and Safety for Technical Processes SAFEPROCESS, Kingston Upon Hull, England, vol. 2, pp. 389-394.

Theilliol D., Noura H., Ponsart J.C. (2002). Fault diagnosis and accommodation of a three-tank system based on analytical redundancy. ISA Transactions, Vol. 41, No. 3, pp. 365-382. 